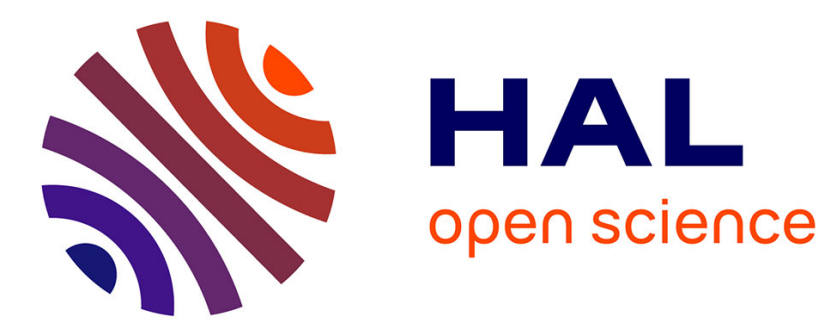

\title{
Temporal activity of spiders and earwigs during winter in apple trees under a Mediterranean climate
}

Sadeq Alzubik Belkair, Christophe Mazzia, Alain Pasquet, Yvan Capowiez

\section{To cite this version:}

Sadeq Alzubik Belkair, Christophe Mazzia, Alain Pasquet, Yvan Capowiez. Temporal activity of spiders and earwigs during winter in apple trees under a Mediterranean climate. Biocontrol Science and Technology, 2018, 28 (9), pp.823-836. 10.1080/09583157.2018.1499870 . hal-02022105

\section{HAL Id: hal-02022105 \\ https://hal-univ-avignon.archives-ouvertes.fr/hal-02022105}

Submitted on 10 Apr 2019

HAL is a multi-disciplinary open access archive for the deposit and dissemination of scientific research documents, whether they are published or not. The documents may come from teaching and research institutions in France or abroad, or from public or private research centers.
L'archive ouverte pluridisciplinaire HAL, est destinée au dépôt et à la diffusion de documents scientifiques de niveau recherche, publiés ou non, émanant des établissements d'enseignement et de recherche français ou étrangers, des laboratoires publics ou privés. 


\title{
Temporal activity of spiders and earwigs during winter in apple trees under a Mediterranean climate
}

\author{
Sadeq Alzubik Belkair ${ }^{a, b}$, Christophe Mazziab ${ }^{b}$ Alain Pasquet ${ }^{c}$ and Yvan Capowiez $^{a}$ \\ aINRA, UMR 1114 Environnement Méditerranéen et Modélisation des Agro-Hydrosystémes, INRA/UAPV, \\ Avignon, France; ${ }^{b}$ UAPV, UMR 7263, IMBE, UAPV/CNRS/IRD, Avignon, France; ${ }^{c}$ CNRS, UR AFPA, Faculté des \\ Sciences et Technologies, University of Lorraine, Vandoeuvre les Nancy, France
}

\begin{abstract}
It is well known that spiders are present in high numbers in orchards and may contribute to biocontrol. Some recent studies in central Europe further showed that some spiders are active year-round and consume pests even in winter. Using cardboard traps laid every two weeks, we carried out a survey to determine which spider and earwig species are active from September to May in an experimental, pesticide-free, apple orchard under a Mediterranean climate. We observed that spider activity was never completely absent. The structure of the spider communities showed a marked seasonality in three periods (so-called 'autumn', 'winter' and 'spring'). Only two spider genera, Philodromus and Trachelas, were highly active in winter (percentage of catches during this season above $40 \%$ ) and six others (Lathys, Clubiona, Gnaphosa, Theridion, Phrurolithus) had moderate activity (between 20 and 40\%). The two earwig species had different patterns of winter activity with Forficula auricularia almost absent whereas F. pubescens was moderately active on trees. Spider community abundance, diversity and evenness significantly decreased between autumn and winter and remained low in the following spring probably because the attractiveness of the traps is much lower at this time of year due to mild temperatures and the presence of leaves on the trees. Winter-active spiders could contribute to pest biocontrol during the cold season and we advocate that the use of broadspectrum pesticides at the end of winter, as classically applied in orchards, may be counter-productive for pest control.
\end{abstract}

\section{KEYWORDS}

Orchard; overwintering; biocontrol; generalist predator; Philodromidae

\section{Introduction}

Today, there is general agreement among the public and, growers that crop protection should rely less on the use of synthetic pesticides and more on agro-ecology principles (Jones et al., 2016; Marliac, Penvern, Barbier, Lescourret, \& Capowiez, 2015). Among these principles, biological control through the promotion of natural enemies and with limited use of pesticides is of prime importance (Beers et al., 2016).

In apple orchards, the rosy apple aphid (Disaphys plantaginea) is one of the main pests (Dib, Jamont, Sauphanor, \& Capowiez, 2016). It is particularly difficult to control due to 
its rapid growth rate and early presence in spring even at low temperatures, i.e. when natural enemies are not yet present in abundance (Dib, Simon, Sauphanor, \& Capowiez, 2010; Minarro, Hemptinne, \& Dapena, 2005). However, this aphid is also present on apple trees throughout the entire winter in a quiescent stage (eggs) and thus the promotion of generalist predators in autumn or winter may limit pest outbreaks in spring (Wyss \& Daniel, 2004).

Schaefer (1977) pointed out that a surprisingly high proportion of spiders were found in a quiescent (not diapause) stage in winter in Germany. The possible implications of the winter activity of generalist predators, and particularly spiders, for biological control were however only recently recognised in pear or apple orchards. In central Europe, Pekar, Michalko, Loverre, Liznarova, and Cernecka (2015) demonstrated the role of spider predation against psyllids under laboratory and field conditions. Winter-active spiders, such as Philodromus and Anyphaena, can feed even at below freezing temperatures (Korenko, Pekar, \& Honek, 2010). Boreau de Roincé, Lavigne, Mandrin, Rollard, and Symondson (2013) used gut content analysis to detect early predation of aphids by spiders in apple orchards and determined the frequency of this phenomena. It is noteworthy that spiders were the main predators within the apple orchards when the first colony fundatrices (aphids emerging from winter eggs) were present, indicating their importance in the early control of aphids (Isaia, Beikes, Paschetta, Sarvajayakesavalu, \& Badin, 2008). Petrakova et al. (2016) also used gut content analysis to detect psyllid predation by Philodromus and Anyphaena in winter and early spring in a pear orchard. They observed a high percentage of spiders with psyllid in their gut contents varying from 10 to $90 \%$ for Philodromus and from 40 to $100 \%$ for Anyphaena during the first year of their survey. These results suggest a greater role for spiders in agro-ecosystems and their contribution to biological control of key pests.

Once the possible roles for spiders in pest biocontrol in winter are recognised, then the species which are active during this period and in early spring need to be determined. A seminal study by Horton, Miliczky, Broers, Lewis, and Calkins (2001) showed that in the state of Washington (US) spiders were mobile until the end of November in apple and pear orchards. Pekar et al. (2015) provided further evidence for central Europe and suggested that Philodromus sp. and Anyphaena accentuata were the dominant spiders active in winter. However no information is available for the Mediterranean climate where winters are known to be warmer promoting greater arthropod activity.

In this study, we used cardboard traps around tree trunks in an apple orchard to address two objectives. First, we determined the abundance of active and inactive spiders in an apple orchard from autumn to spring. Secondly, we differentiated spider species depending on their winter or early spring activity. This study provides information on the activity of generalist predators in a European orchard during winter/spring, but with a Mediterranean climate. Located in southeastern France, the study is a first step towards understanding the possible role of these predators in the biological control of pests inhabiting these orchards during winter or early spring.

\section{Material and methods}

\section{The study orchard}

The study was conducted at Institut National de la Recherche Agronomique (INRA), Avignon (south-eastern France) in an experimental apple orchard (N 43.917137 E 
4.880482) from the 28 August 2015 to the 30 May 2016 with one or two sampling dates per month. The orchard had been pesticide-free for 5 years. It is surrounded by a double hedge-row (approximately $10 \mathrm{~m}$ high and $2 \mathrm{~m}$ wide) in the north, a single hedge-row in the south, arable land to the west and a small road and buildings to the east. The 0.25 ha orchard was planted in 2005 with 10 rows of Golden Delicious apples. The rows were oriented in an east-west direction and spaced $3 \mathrm{~m}$ apart. The planting distance between trees was $2 \mathrm{~m}$ within rows and average tree height was $1.70 \mathrm{~m}(\mathrm{SD}=0.17 ; n=$ 30). The inter-row is made up of resident grasses mowed three times a year.

The climatic conditions (minimum, mean and maximum daily temperatures) were recorded by a weather station located $500 \mathrm{~m}$ from the orchard.

\section{Sampling strategy}

It is always difficult to comprehensively sample the spiders or arthropods inhabiting orchards since collection depends on their preferred strata and diurnal activity. In this study, we focused on spiders that are able to feed on winter stages of rosy apple aphids (eggs and emerging females). Thus spiders present in the trees (trunk and canopy) between the return of winged aphids on apple trees in autumn (October) and the development of aphid colonies in spring (April) were targeted. Following the protocol of Horton et al. (2001), we used corrugated cardboard traps (single-fluted) but with two sampling strategies. Traps (10 $\mathrm{cm}$ wide

and $50 \mathrm{~cm}$ long) completely encircled the trunk of each tree in the orchard at the end of August using adhesive tape at a height of about $50 \mathrm{~cm}$ height. The first strategy used 'static' traps and focused on the cumulative number of spiders found on each date (some spiders entered and others possibly left). Every two weeks until the end of December and once a month in January, February and March (because a lower activity was then expected) and then again every two weeks in April and May, 20 bands (2 per row) were randomly chosen and individually placed into plastic bags and numbered according to tree identity (row and $n^{\circ}$ of tree in this row). Care was taken not to lay traps on the same tree during the experiment. The second strategy used 'dynamic' traps and aimed to trap spiders that entered a temporary (2-week) trap, thus the so-called active spiders. This was simply achieved by replacing, at each date, the previously removed cardboard traps with new ones and by harvesting them two weeks later. The two sampling strategies provided different and complementary information on spiders and their activity, static and dynamic traps, respectively. However this information should not be regarded as a comprehensive view of all the spiders present at every date in the trees (some species or individuals do not need such shelters). Moreover for each species, the efficiency of these traps may vary with time (species can seek shelter for overwintering or nesting or diurnal/nocturnal sites).

The bags were opened in the laboratory and all the arthropods found inside were stored in $70 \%$ ethanol for subsequent identification. As a great majority of the spiders caught were immature, especially in winter, individuals were mainly identified at the genus level using the reference website (https://araneae.unibe.ch/) for identification keys; only adults were identified to the species level.

\section{Statistical analysis}

The mean abundance (and SE) of spiders caught per trap was computed for each date in each sampling strategy (recent and cumulative traps). 
The structure of the spider communities in dynamic traps and its variation with time were analysed using a principle component analysis (PCA). The resulting $2 \mathrm{D}$ projections were analysed with a Hierarchical Ascending Classification to determine different groups (Hill, 1973). We estimated the percentage of winter activity for each taxon as the total abundance caught in dynamic traps during this season relative to the total caught throughout the entire experiment in the same traps.

We computed the characteristics of the spider communities caught in the dynamic traps at each sampling date, i.e. abundance, Shannon index of diversity and Pielou index of evenness (using the genus level). The proportion of adults was also computed. To compare these characteristics between seasons, we applied a nested ANOVA (proportion of adults were arcsine square root transformed) with sampling dates nested within the season factor.

All computations were done using the $\mathrm{R}$ software and the 'vegan' package.

\section{Results}

\section{Total arthropod abundance over time}

Only two groups of arthropods were found in large abundance (Dermaptera and Arachnida), representing more than $90 \%$ of the total arthropods caught. Other minor arthropods were Coccinellidae (Scymnus genus), Carabidae and Staphylinidae. Dermaptera was represented by two species (Forficula auricularia and F. pubescens).

We found 3744 spiders in the 579 traps (2743 and 1001 in static and dynamic traps respectively). The temporal dynamics was clear in the cumulative traps with a gradual increase from 4.0 in September to 19.4 spiders per trap and thus per tree in midDecember. Then the mean abundance decreased in a non-linear manner to reach a minimal value of 1.2 individuals per tree at the end of May (Figure 1). The dynamics of dynamic traps was different with high values (above 4 spiders per trap) from September to the end of mid-November, after which the mean abundance of active spiders remained low (between 1.0 and 3.4 individuals per trap) until the end of May with the noticeable exception at the beginning of April with a peak of 5.7 active spiders per tree. Two genera were highly dominant when static and dynamic traps were grouped together: Heliophanus sp and Nurscia sp with respectively, 23.1 and 18.6\% of the spiders sampled. The remaining taxa then ranked in the following order Phrurolithus sp., Lathys sp., Micaria sp., Theridion sp., Zelotes sp.. Gnaphosa sp., Aphantaulax sp., Icius sp., Scotophaeus sp., Clubiona sp. and Philodromus sp. with values between 6.7 and $2.6 \%$.

The two species of earwigs recorded showed marked differences in their seasonal activity. F. auricularia was only active from September to mid-November whereas F. pubescens was active from September to the end of December (Figure 3).

Mean daily temperatures gradually decreased from 25 to $7.5^{\circ} \mathrm{C}$ between September and mid-November (Figure 2). They further decreased, despite a marked increase at the end of November, to $2.5^{\circ} \mathrm{C}$ at the end of January. At this date, a pronounced increase was observed (to reach $10^{\circ} \mathrm{C}$ at the very beginning of February) followed by a gradual increase, at least until the end of April (up to $16^{\circ} \mathrm{C}$ ). 


\section{Recent traps}

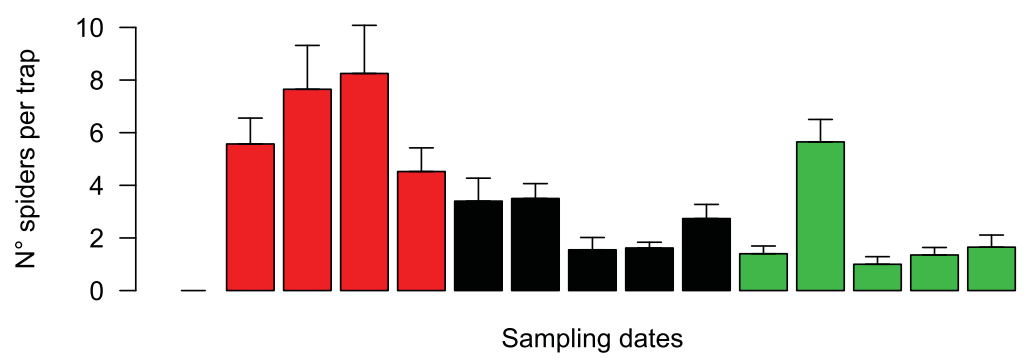

\section{Cumulative traps}

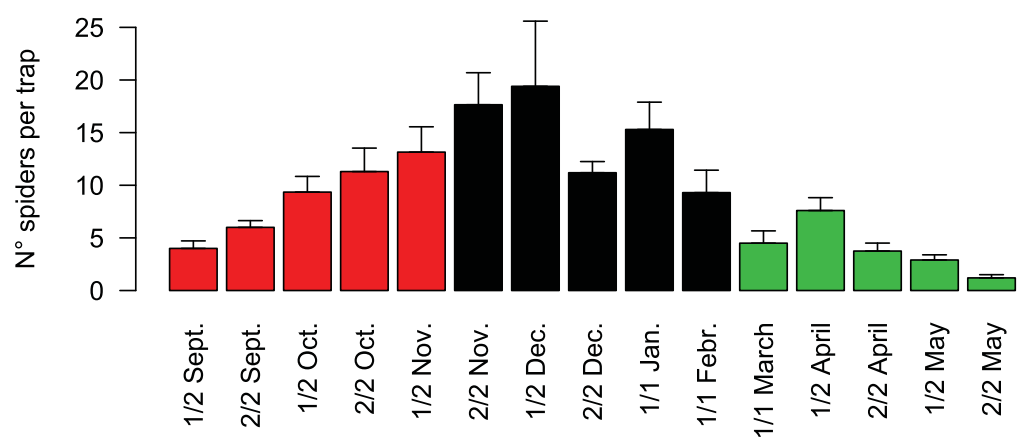

Figure 1. Mean (and SE) abundance of spiders in dynamic (temporary) or static (entire sampling period) cardboard traps in the experimental orchard free of pesticides $(n=20)$. Colours separated the three seasons defined by the Hierarchical Ascending Classification: dark grey for autumn, black for winter and soft grey for spring (see Figure 3).

\section{Seasonal dynamics of spider communities}

The ascending hierarchical classification applied to the abundance of active spiders found at each date in dynamic traps clearly differentiated three groups (Figure 4(a)): from date 2 to date 5 (September to mid-November), date 6 to date 10 (end of November to February) and date 11 to date 15 (March to May). Even if these groups did not strictly follow the definition of the seasons we will herein refer to them as 'autumn', 'winter' and 'spring' groups.

The PCA analysis further showed the ordination of the dates around a circle (from date 2 bottom-left to date 15 bottom-right; Figure 4(b)). The first two axes of this PCA explained $47 \%$ of the variability. The three so-called seasons were well separated in the PCA with the first axis separating autumn from the two others seasons and the second axis separating mainly winter from spring (Figure 4(d)). Some taxa appeared to be clearly associated with each season, for example Heliophanus in spring, Nurscia in autumn and Philodromus in winter (Figure 4(c)).

\section{Classification of spiders according to their winter activity}

For each taxa, winter activity was defined as the total abundance caught in dynamic traps during this season relative to the total caught throughout the entire experiment in the 


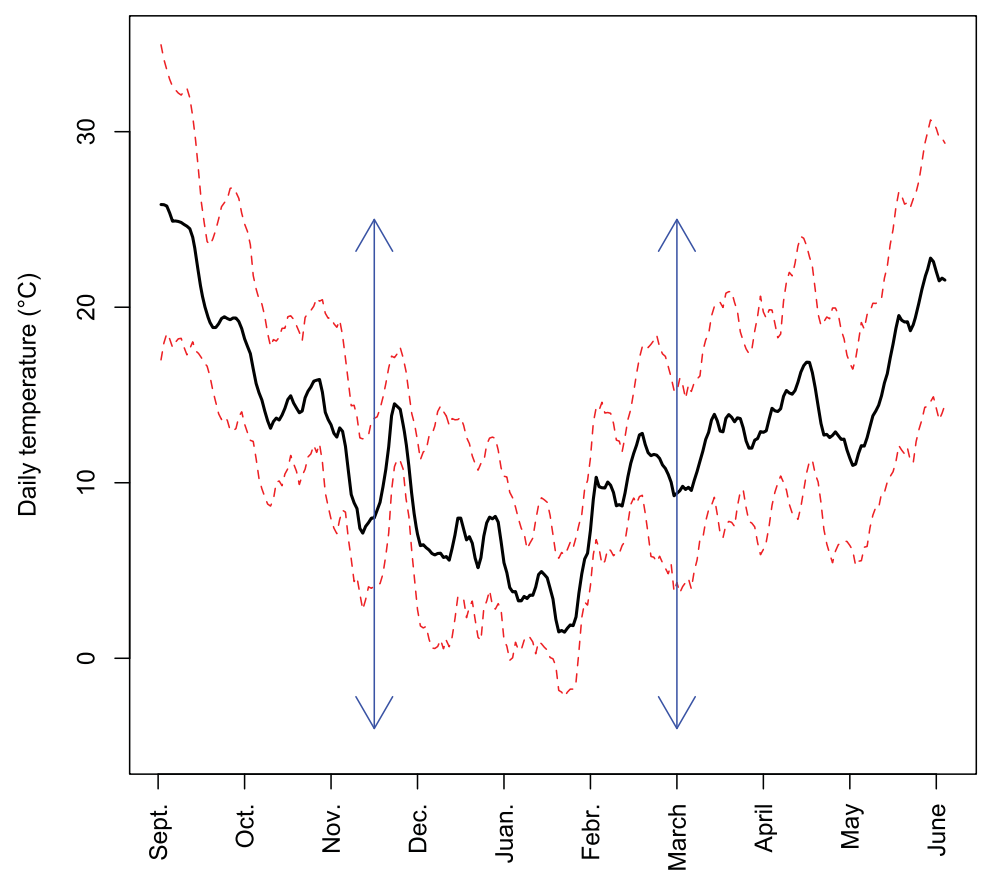

Figure 2. Mean, minimum and maximal values for daily temperatures $\left({ }^{\circ} \mathrm{C}\right)$ recorded close to the orchard from the 1th of September to the 1th of June. Vertical arrows indicate the separation between the seasons as defined by the Hierarchical Ascending Classification (see Figure 3).

same traps. This percentage of winter activity was very different for each taxon and ranged from 3\% for Micaria sp. to 69\% for Philodromus sp. (Figure 5). Only two taxa had a percentage of winter activity higher than $45 \%$ (Philodromus and Trachelas sp.) and were classified as having a high winter activity. Six taxa had intermediate percentages, between 25 and $40 \%$ of winter activity and were classified as spiders with moderate winter activity. The last eight taxa had percentages lower than $20 \%$ and were classified as spiders with low winter activity. The threshold values of 25 and $45 \%$ were arbitrarily chosen. If the difference (about 10\%) between moderate and low winter activity was significant, Trachelas sp. could have been classified into the second category.

Instead of presenting all the taxa, we chose to show two typical and abundant taxa in each category. All the curves had roughly the same shape with generally one peak or a plateau for static or dynamic traps. For spiders with a high winter activity, the highest abundance in the static traps occurred late (at date 9 for both species) whereas the peak or plateau in the dynamic traps lasted until date 6 or 7 (Figure 6). For spiders with moderate winter activity, the peak of abundance in static traps could occur late (date 9 for Clubiona) but the peak for dynamic traps occurred sooner (date 5). Low winter activity was characterised by a peak occurring sooner: at date 6 or before for static traps and at date 2 to 3 for dynamic traps.

The two earwig species had quite different winter activity with only $5.4 \%$ for $F$. auricularia and $37.3 \%$ for F. pubescens. Following the same classification ranking according to their winter activity as for the spiders, F. auricularia has low winter activity as expected. F. pubescens, however, had moderate winter activity. 


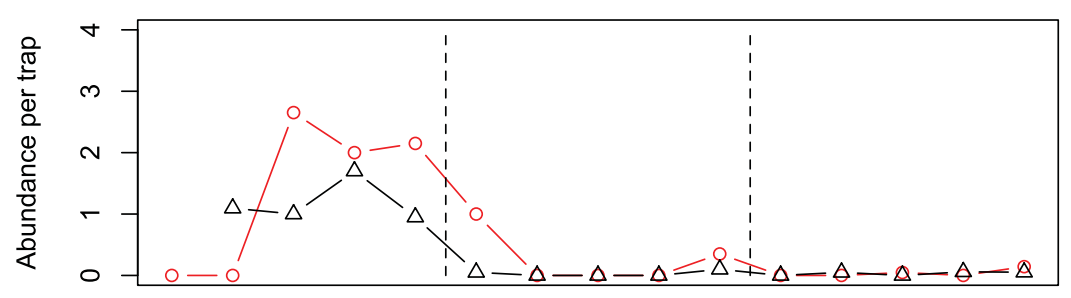

F. pubescens

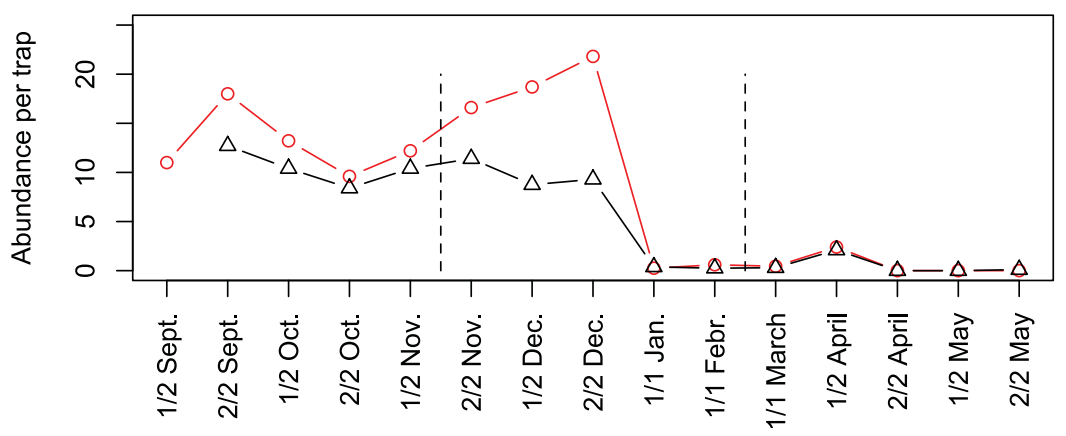

Figure 3. Mean abundance caught in dynamic (black triangle) and static traps (grey circle) of both earwig species caught in the experimental orchard free of pesticides. Dynamic traps were repeatedly attached to trees whereas static traps were attached once in August.

\section{Characteristics of the spider communities depending on the seasons}

A significantly higher abundance, species richness, diversity and evenness were observed in autumn (Table 1). In winter, the spider abundance decreased significantly but still had a significantly higher species richness, diversity and equitability than in spring. The percentage of adults within the spider community remained very low in autumn and winter (around 10\%) but then greatly increased in spring.

\section{Discussion}

\section{Many spiders are active during the Mediterranean winter}

In the past, arthropod winter activity was thought to be very limited in orchards especially after leaves had fallen. This was associated with low temperatures, the scarcity of prey and the decrease in shelter or hunting sites when no leaves are present. However, since the studies of Korenko et al. (2010) and Korenko and Pekar (2010), it is now recognised that some spider species (Anyphaena accentuata and Philodromus cespitus) are active in winter, even at negative temperatures for A. accentuata, in pear orchards in the Czech republic. In apple orchards under Mediterranean climate, Boreau de Roincé et al. (2013) further showed, using gut content analysis, that early in the season (from the end of March to end of April), some spiders were found to have eaten aphid emerging females. These were Clubiona sp., A. accentuata and Philodromus sp. with 29.2, 18.8 


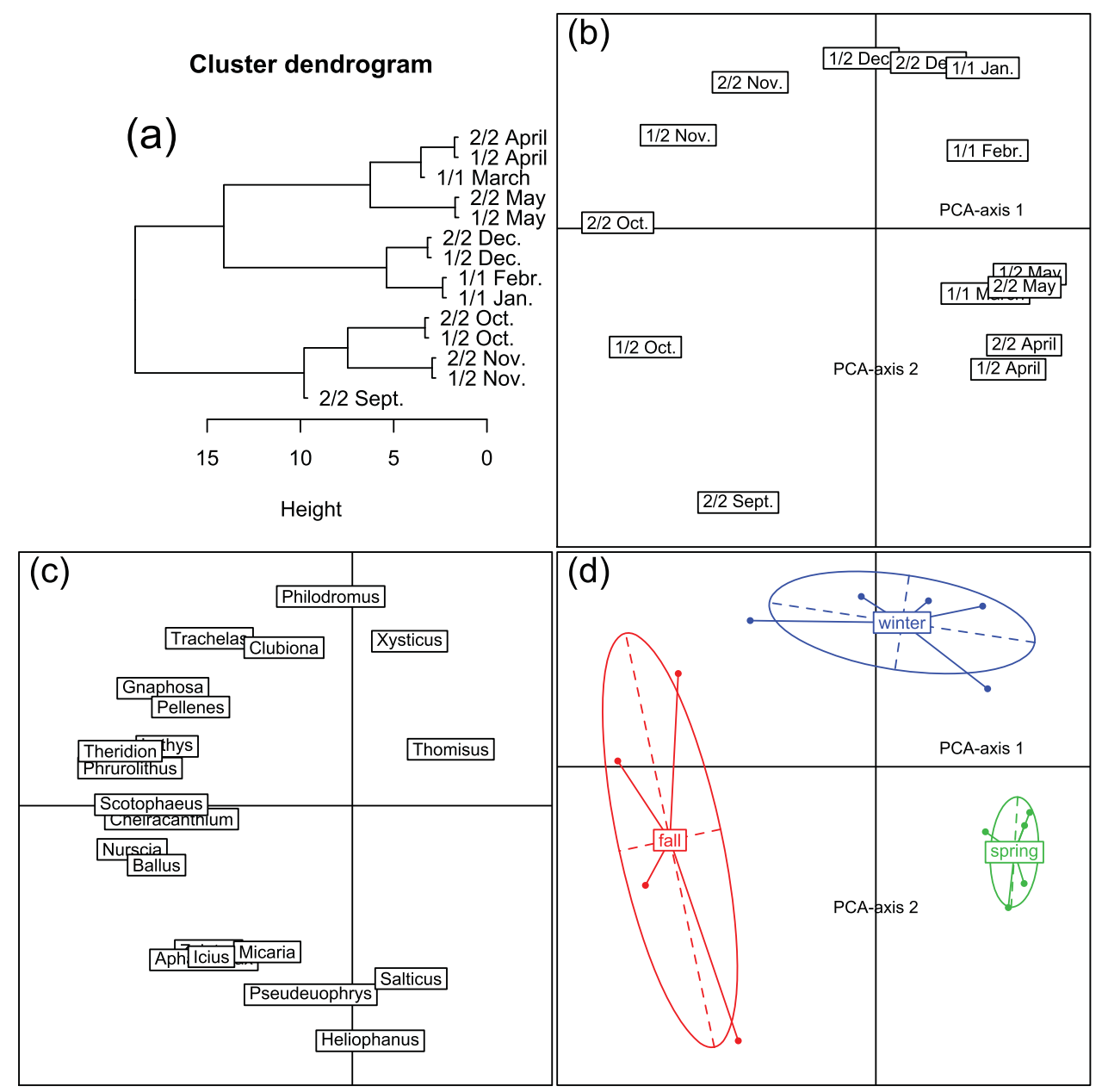

Figure 4. Analysis of the structure of the active spider communities found in dynamic traps (repeatedly attached) as a function of sampling date: (a) Hierarchical Ascending Classification applied to the results of the PCA; (b) projections of the sampling date (note that there are no temporary, repeatedly attached traps in the beginning of September) in the first two axes of the PCA; (c) projections of the spider genus in the first two axes of the PCA; (d) $80 \%-C l$ ellipses for each season as defined by the HAC.

and $3.7 \%$ of them being positive respectively, from recent predation of aphids. However, rosy apple aphids are present during the entire winter, first as eggs and then as fundatrices in apple orchards (Dib et al., 2010). In a similar way, the psyllid Cacopsylla piri is present in pear orchards all winter long (Michalko, Petráková, Sentenská, \& Pekár, 2017). It is thus crucial to determine which spiders may be active in late-autumn, winter and early spring (periods generally without pesticide applications) in order to evaluate their possible role in the biological control of pests inhabiting orchards at these times. Cardboard traps are classically used to assess spider communities overwintering in orchards (Bogya, Szinetar, \& Marko, 1999; Miliczky, Horton, \& Calkins, 2008; Pekar, 1999) but do not provide information on which spiders are active during winter. Only the removal of temporary (dynamic) cardboard traps can provide this information (Horton et al., 2001). 


\section{Recent traps}

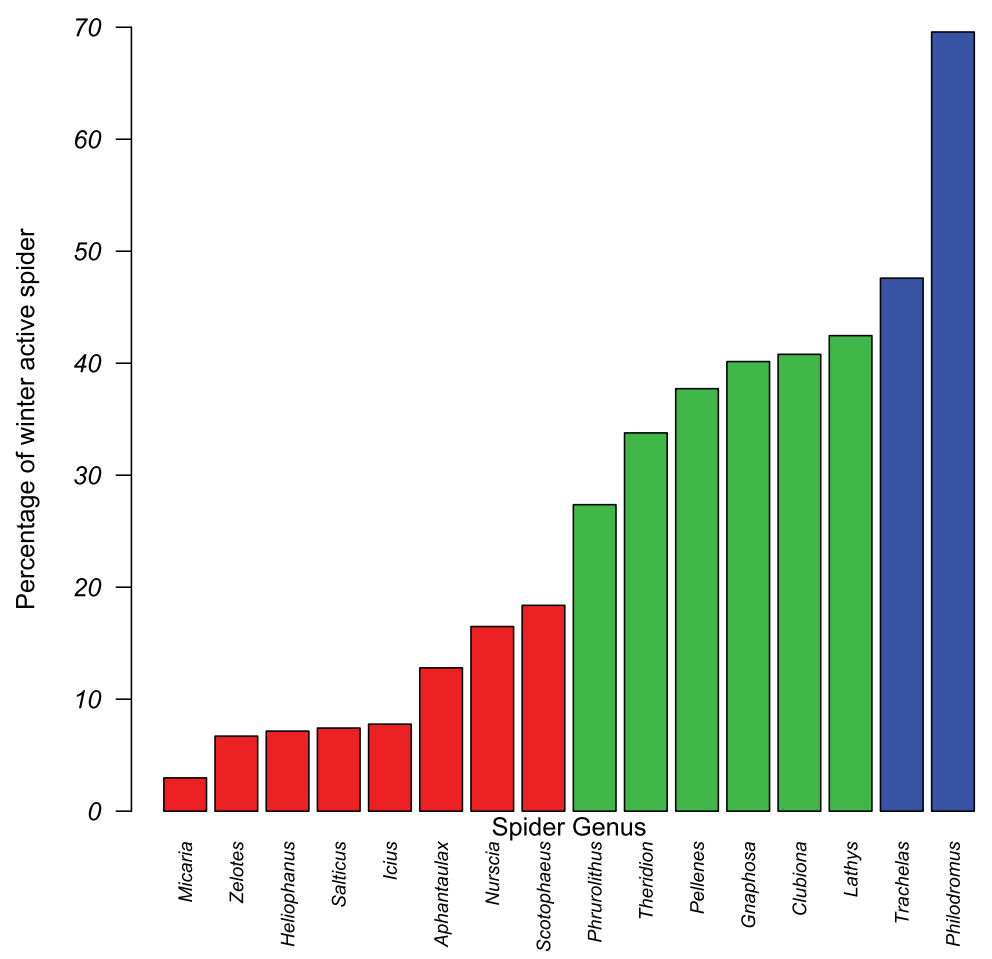

Figure 5. Bar plot of the percentage of winter-activity for the main spider genera. Winter activity was defined as the abundance caught in dynamic traps laid in winter divided by the total caught in the three seasons (colours separated spider genera with low (dark grey), moderate (soft grey) or high (black) winter activity).

Hierarchical ascending classification applied to the PCA projections of the spiders found in our traps showed that spider communities changed through time but was limited to the dominant species from September to May This resulted in a clear distinction of three temporal groups (with mid-November and March as thresholds), hereafter called seasons. The first threshold value was concomitant with a marked decrease in the mean daily temperature up to $7.5^{\circ} \mathrm{C}$. The second threshold value did not correlate to a clear increase in the temperature but to the period where the mean daily temperatures become consistently above $10^{\circ} \mathrm{C}$. We did not expect clear-cut threshold values since not all spider species have the same tolerance for cold temperatures (Korenko et al., 2010; Schaefer, 1977).

A significant finding from our study is that spider activity was recorded throughout the entire winter. The percentage of dynamic traps where no spiders were sampled was very low (about 15\%). During the coldest periods in January, with average daily temperatures between 2 and $5^{\circ} \mathrm{C}$, the mean number of spiders was still 1.62 individuals per tree in dynamic traps. It is worth noting that at this time, the spider community was still rather diversified with 16 taxa, and for three the abundance was above 10\% (Trachelas, Nurscia and Philodromidus) and three others made up between 10 and 5\% (Lathys, 


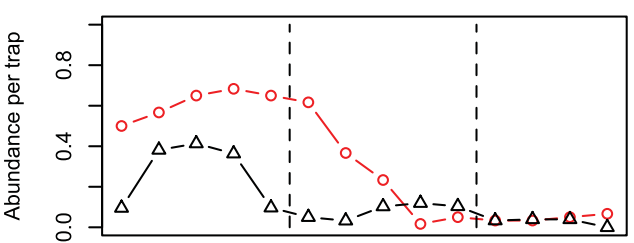

Lathys

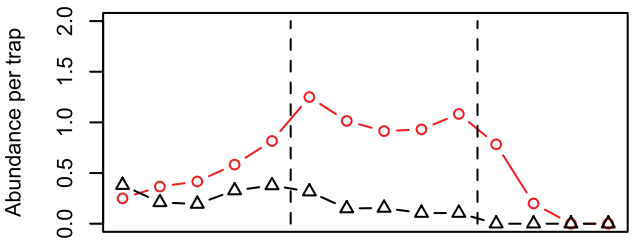

Philodromus
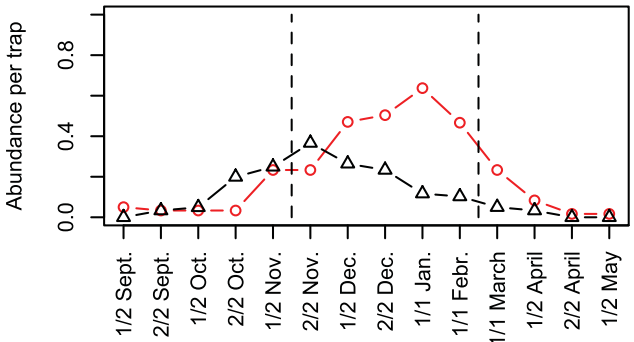

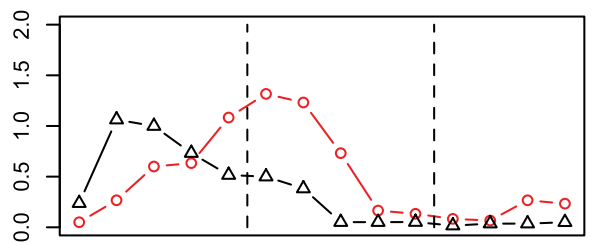

Clubiona

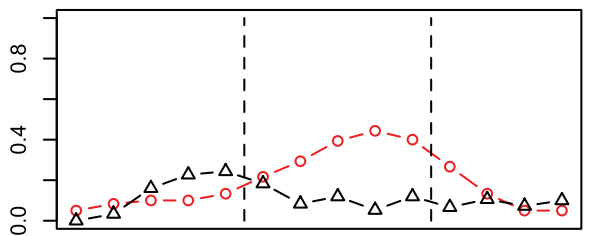

Trachelas

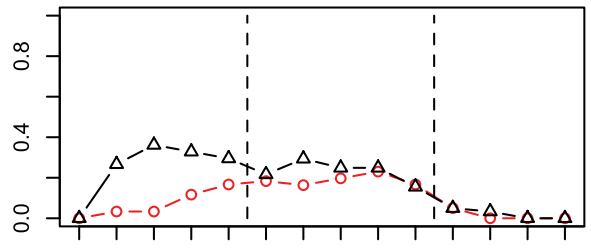

范

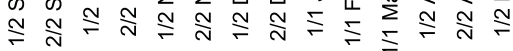

Figure 6. Mean abundance caught in dynamic (black triangle) and static traps (grey circle) for six chosen genera corresponding to spiders with a low (first row), moderate (second row) or high (third row) winter activity. Dynamic traps were repeatedly attached whereas static traps were attached once in August.

Clubiona and Scotophaeus) of total spider abundance. The overall winter abundance was much lower than in autumn with a decrease of $60 \%$ (from 6.50 to 2.56 spiders per tree) and then remained low in spring (2.21 spider per tree). During the same period, the Shanon

Table 1. Mean (and SE) values for the characteristics of the spider communities caught for each season in recent traps in the experimental orchard free of pesticides. Values bearing a different letters are significantly different.

\begin{tabular}{|c|c|c|c|c|c|}
\hline Season & $\begin{array}{l}\text { Abundance (per } \\
\text { trap) }\end{array}$ & $\begin{array}{r}\text { Species } \\
\text { richness }\end{array}$ & $\mathrm{H}^{\prime *}$ & $\mathrm{~J}^{\prime \$}$ & $\begin{array}{c}\text { Percentage of } \\
\text { adults }\end{array}$ \\
\hline $\begin{array}{l}\text { Autumn } \\
\text { (September } \rightarrow \text { mid } \\
\text { November) }\end{array}$ & $6.46^{\mathrm{a}}(0.62)$ & $3.97^{\mathrm{a}}(0.78)$ & $1.18^{\mathrm{a}}(0.05)$ & $0.73^{\mathrm{a}}(0.01)$ & $11.88^{b}(1.22)$ \\
\hline $\begin{array}{l}\text { Winter } \\
\quad \text { (mid November } \rightarrow \\
\text { February) }\end{array}$ & $2.55^{\mathrm{b}}(0.33)$ & $2.43^{\mathrm{b}}(0.46)$ & $0.70^{\mathrm{b}}(0.06)$ & $0.51^{\mathrm{b}}(0.03)$ & $11.14^{\mathrm{b}}(2.96)$ \\
\hline $\begin{array}{l}\text { Spring } \\
\quad \text { (March } \rightarrow \text { May) }\end{array}$ & $2.25^{\mathrm{b}}(0.27)$ & $1.85^{\mathrm{c}}(0.21)$ & $0.45^{\mathrm{c}}(0.04)$ & $0.36^{\mathrm{c}}(0.02)$ & $58.36^{\mathrm{a}}(16.77)$ \\
\hline
\end{tabular}

*Diversity index of Simpson.

\$Evenness index of Pielou. 
index of diversity also decreased from 1.18 to 0.70 . This contrasts sharply with the results obtained by Korenko and Pekar (2010) in central Europe where the spider community was highly dominated by three genera (Anyphaena, Theridion and Philodromus) representing $89 \%$ of the total spider abundance. Indeed, in our study the three most abundant genera (Philodromus, Phrurolithus and Trachelas) accounted for only $36 \%$ of the community in winter.

Horton et al. (2001) previously observed sharp declines in abundance between November and December in northwestern United States. However the abundance of active spiders was low at the end of December and these authors stopped their survey, possibly because winters are more extreme in this region. The static traps further corroborated these results and showed a regular increase in spider density from September to midDecember. Horton et al. (2001) did not provide information on the temperature in their orchards, but we can compare our observations with those from Korenko et al. in Czech Republic (2010; Figure 4) and it is clear that winter temperatures in Avignon in 2015 were much milder with a mean difference of about $+7^{\circ} \mathrm{C}$ in December and January. These authors also determined temperature thresholds for activity of $A$. accentuata and Philodromus sp. They showed that these thresholds were about 1 and $4^{\circ} \mathrm{C}$ respectively for these two species. If these same thresholds were applied to our orchard, this would mean that at least these two species could be active throughout the entire winter.

Spiders may not be the only arthropods active in winter in orchards and indeed we observed that one of the predominant earwig species ( $F$. pubescens) had a moderate winter activity (i.e. more than $25 \%$ of the catches in winter) whereas the other (F. auricularia) had none. These observations of the marked difference between these two species are in agreement with those made by Lordan, Alegre, Moerkens, Sarasua, and Alins (2015) in Spanish apple orchards. The implications of this finding are not easy to determine since F. pubescens is known to have a more diversified feeding regime (Romeu-Dalmau, Espadaler, \& Pinol, 2011).

\section{Ecological significance of cardboard bands}

Cardboards traps are the dominant measure for spider and earwig activity in orchards in autumn or winter (Bogya et al., 1999; Fye, 1985; Tamaki \& Halfhill, 1968). These traps allow high abundances to be observed due to the fact that they can actually act as shelters for most of the arboreal spiders that are assumed to be wintering there. However, not all spider species spend the whole winter in a resting state as recently demonstrated by Korenko and Pekar (2010) and Pekar et al. (2015). Using the protocol of Horton et al. (2001), i.e. traps sampled every two weeks, we were able to determine which spider genera were predominantly active in the trees in winter. The exact ecological significance of this trap is not easy to define since spiders may use them for different reasons: nocturnal or diurnal shelters or overwintering sites. Even in the latter case, there is evidence that some spiders use them only when the conditions become extreme (Korenko \& Pekar, 2010) and then leave them during milder days or nights. Our results cannot determine why spiders entered cardboard traps, they only prove that the spiders caught were active, even for a few hours, during the last two weeks and then moved again to find a new shelter. Nevertheless, this suggests that the abundance of spiders in late spring 
decreased because leaves are once again present and temperatures are mild, thus the shelters become less and less and attractive.

Some authors observed that the abundance of spiders, assessed using cardboard traps, decreased between autumn and spring and assumed that this was due to winter mortality and/or intra-guild predation (Pekar, 1999). At first glance, we also observed a great decline in spider abundance in the static traps during winter when the mean air temperatures dropped from 5 to $1^{\circ} \mathrm{C}$, with on average 19.4 at the beginning of December to 9.3 spiders per trap in January (the spring decrease cannot be easily interpreted as explained above). This decrease was pronounced for spiders with no winter activity (see Scotophaeus and Phrurolithus in Figure 5). These species may have died or been subjected to intra-guild predation by spiders with intermediate or high winter activity.

Our findings also suggest that, apart from intra-guild predation, prey abundance on apple trunks may be enough to sustain spider and earwig populations during winter, although some spiders are able to starve for long periods of time. These two observations - high presence of winter-active spiders and likely presence of prey (some being apple pests such as aphid eggs) - lead us to think that the first pesticides applied in apple orchards, very often mineral oils with low selectivity (Biondi et al., 2015), should be reconsidered, especially if the sensitivities of spiders or earwigs is similar or higher than those of pests.

\section{Conclusions}

We believe it is time for a paradigm shift in biocontrol based on generalist predators in perennial crops (orchards, vineyards). Historically, it has been considered that during fall and winter months, when leaves are no longer present on trees, natural enemies remain inactive in a resting stage. In contrast, we demonstrated that during winter months, under a Mediterranean climate, some generalist predators, and especially spiders, are indeed mobile and active. These results complement similar studies from central Europe. Even if not directly assessed in our study, these predators may be able to feed on the quiescent stages of some pests (aphids or psyllids for example). Moreover, some spiders with low winter-activity overwintered in remarkable quantities in the provided shelters around tree trunks. We also assume that these spiders will play an active role in biocontrol in early spring as soon as the temperatures increase or in winter if they become milder because of climate change. Our results suggest that (i) habitat manipulation, using cardboard shelters around tree trunks, could be an interesting way to increase biocontrol of pests overwintering in the tress and (ii) the systematic use of broad spectrum pesticides in early spring could prevent these generalist predators from controlling pests that are not yet in an outbreak phase. Further studies are thus required to evaluate the winter or early-sprig efficiency of these natural enemies compared to pesticide application.

\section{Disclosure statement}

No potential conflict of interest was reported by the authors.

\section{Funding}

AS was supported by a scholarship from the Libyan embassy. 


\section{References}

Beers, E. H., Mills, N. J., Shearer, P. W., Horton, D. R., Milickzy, E. R., Amarasekare, K. G., \& Gontijo, L. M. (2016). Nontarget effects of orchard pesticides on natural enemies: Lessons from the field and laboratory. Biological Control, 102, 44-52.

Biondi, A., Campolo, O., Desneux, N., Siscaro, G., Palmeri, V., \& Zappalà, L. (2015). Life stagedependent susceptibility of Aphytis melinus DeBach (Hymenoptera: Aphelinidae) to two pesticides commonly used in citrus orchards. Chemosphere, 128, 142-147.

Bogya, S., Szinetar, C. S., \& Marko, V. (1999). Species composition of spider (Araneae) assemblages in apple and pear orchards in the Carpathian Basin. Acta Phytopathologica et Entomologica Hungarica, 34, 99-121.

Boreau de Roincé, C., Lavigne, C., Mandrin, J.-F., Rollard, C., \& Symondson, W. O. C. (2013). Earlyseason predation on aphids by winter-active spiders in apple orchards revealed by diagnostic PCR. Bulletin of Entomological Research, 103, 148-154.

Dib, H., Jamont, M., Sauphanor, B., \& Capowiez, Y. (2016). The feasability and efficacy of earlyseason releases of a generalist predator (Forficula auricularia L.) to control populations of the RAA (Dysaphis plantaginea Passerini) in Southeastern France. Bulletin of Entomological Research, 106, 233-241.

Dib, H., Simon, S., Sauphanor, B., \& Capowiez, Y. (2010). The role of natural enemies on the population dynamics of the rosy apple aphid, Dysaphis plantaginea Passerini (Hemiptera Aphididae) in organic apple orchards in south-eastern France. Biological Control, 55, 97-109.

Fye, R. E. (1985). Corrugated fiberboard traps for predators overwintering in pear orchards. Journal of Economic Entomology, 78, 1511-1514.

Hill, M. O. (1973). Reciprocal averaging: An eigenvector method of ordination. The Journal of Ecology, 61, 237-249.

Horton, D. R., Miliczky, E. R., Broers, D. A., Lewis, R. R., \& Calkins, C. O. (2001). Numbers, diversity, and phenology of Spiders (Araneae) overwintering in cardboard bands placed in pear and apple orchards of central Washington. Annals of the Entomological Society of America, 94, 405414.

Isaia, M., Beikes, S., Paschetta, M., Sarvajayakesavalu, S., \& Badin, G. (2008). Spiders as potential biological controllers in apple orchards infested by Cydia spp. (Lepidoptera: Tortricidae). Proceedings of the 24th European Congress of Arachnology, Bern.

Jones, V. P., Mills, M. J., Brunner, J. F., Horton, D. R., Beers, E. H., Unruh, T. R., ... Jones, W. E. (2016). From planning to execution to the future: An overview of a concerted effort to enhance biological control in apple, pear, and walnut orchards in the western US. Biological Control, 102, 1-6.

Korenko, S., \& Pekar, S. (2010). Is there intraguild predation between winter-active spiders (Araneae) on apple tree bark? Biological Control, 54, 206-212.

Korenko, S., Pekar, S., \& Honek, A. (2010). Predation activity of two winter-active spiders (Araneae: Anyphaenidae, Philodromidae). Journal of Thermal Biology, 35, 112-116.

Lordan, J., Alegre, S., Moerkens, R., Sarasua, M. J., \& Alins, G. (2015). Phenology and interspecific association of Forficula auricularia and Forficula pubescens in apple orchards. Spanish Journal of Agricultural Research, 13. doi:10.5424/sjar/2015131-6814

Marliac, G., Penvern, S., Barbier, J.-M., Lescourret, F., \& Capowiez, Y. (2015). Impact of crop protection strategies on natural enemies in organic apple production. Agronomy for Sustainable Development, 35, 803-813.

Michalko, R., Petráková, L., Sentenská, L., \& Pekár, S. (2017). The effect of increased habitat complexity and density-dependent non-consumptive interference on pest suppression by winteractive spiders. Agriculture, Ecosystems and Environment, 242, 26-33.

Miliczky, E. R., Horton, D. R., \& Calkins, C. O. (2008). Observations on phenology and overwintering of spiders associated with apple and pear orchards in south-central Washington. Journal of Arachnology, 36, 565-573. 
Minarro, M., Hemptinne, J.-L., \& Dapena, E. (2005). Colonization of apple orchards by predators of Dysaphis plantaginea: Sequential arrival, response to prey abundance and consequences for biological control. Biocontrol, 50, 403-414.

Pekar, S. (1999). Some observations on overwintering of spiders (araneae) in two contrasting orchards in the Czech Republic. Agriculture, Ecosystems and Environment, 73, 205-210.

Pekar, S., Michalko, R., Loverre, P., Liznarova, E., \& Cernecka, L. (2015). Biological control in winter: Novel evidence for the importance of generalist predators. Journal of Applied Ecology, $52,270-279$.

Petrakova, L., Michalko, R., Lovere, P., Sentenska, L., Korenko, S., \& Pekar, S. (2016). Intraguild predation among spiders and their effect on the pear psylla during winter. Agriculture, Ecosystems and Environment, 233, 67-74.

Romeu-Dalmau, C., Espadaler, X., \& Pinol, J. (2011). Abundance, interannual variation and potential pest predator role of two co-occuring earwig species in citrus canopies. Journal of Applied Entomology, 136, 501-509.

Schaefer, M. (1977). Winter ecology of spiders (araneida). Zeitschrift für Angewandte Entomologie, $83,113-134$.

Tamaki, G., \& Halfhill, J. E. (1968). Bands on peach trees as shelters for predators of the green peach aphid. Journal of Economic Entomology, 61, 707-711.

Wyss, E., \& Daniel, C. (2004). Effects of autumn kaolin and pyrethrin treatments on the spring populations of Dysaphis plantaginea in apple orchards. Journal of Applied Entomology, 128, $147-149$. 